\title{
Transformation of the values of Generation Z - residents of the digital society of sustainable development
}

\author{
Mikhail Bresler ${ }^{*}$, Svetlana Galiullina, and Daria Gerasimova \\ Ufa State Petroleum Technological University, St. Kosmonavtov 1, 450062 Ufa, Russia
}

\begin{abstract}
The transition to a society of sustainable development is possible only when the priorities and values of the active part of society are changing. From the values of individualism, the weak ties of corporatism, the extensive growth of an industrial society to the values of networked solidarity, social justice, the strong ties of the information/digital society. The transition to a new level of civilizational development not only contributed to the transformation of the economy, politics and the social sphere under the influence of digital technologies, but played a significant role in the formation of Generation Z (born in the late 20th and early 21 st centuries). The article contains study material that was carried out at the Ufa State Petroleum Technological University in the summer of 2020.
\end{abstract}

\section{Introduction}

Starting with the reports of the Rome Club [7] of the 1970s scientific forecasts show a fairly high probability of a negative forecast which is supported as a comparison of forecasts with a true picture of the current state of the political, economic, sociocultural sphere of 1990-2000. The negative development forecast is supported by various concepts of the intervention of random negative factors by N. Taleb, the disintegration of society into a robotic elite and the marginalized masses by N. Harari. There is an understanding of the existence of fundamental problems in modern society. The leaders of developed countries and international organizations declare their adherence to the values of social sustainable development. Despite the fact that the ideas of sustainable development cover broad strata of the population of developed countries, observations of the activities of contemporaries cannot be considered positive. In contrast to the declared values, in reality, people tend to use natural resources, harming nature. This leads to rather modest results in the implementation of global plans. As noted "Despite initial efforts the world has not achieved the momentum needed to achieve most of the 169 targets set under these goals." [8]. By now it has not been possible to create the prerequisites for solving the four global problems highlighted in the mentioned report: "growing inequality, climate change, loss of biodiversity and an increase in the volume of human waste to a level that exceeds the capacity of recycling" (GBO.2019). We see the reason for this in the persisting typical values of the previous stages of civilizational development - an industrial society the values

* Corresponding author: bremmaster@yandex.ru 
of which are opposite to the values of sustainable development. Sustainable development presupposes reasonable consumption, waste-free production or with minimal waste, production of energy from renewable sources or with minimal impact on nature. In the political field in order to establish an equitable distribution of resources it is necessary to have elements of direct democracy associated with the possibility of taking part in the discussion and resolution of significant issues affecting the whole society of wide sections of the population. The industrial technologies, even the latest ones, created with taking into account the impact on the ecosphere, do not allow to fully achieve a solution of the problems of sustainable harmonious development. From the point of view of the social factor, the need to adapt to the conditions of the constant financial, political, epidemiological crisis does not contribute to the formation of the values of sustainable development among the population.

At the beginning of the 21 st century, against the background of a permanent crisis, there is a process of formation of an information/digital society based on digital technologies, the improvement of which is possible with the achievement of dynamic stability of the economic, political and social sphere which is more consistent with the model of sustainable development than itisin the industrial society of the 20th century. The creation, promotion and consumption of digital technology products are different from industrial ones; their development requires the creation and strengthening of the product image within the framework of consumer compliance values more than increasing production efficiency by reducing costs. A paradigm change requires a radical change in people's consciousness, a change in value priorities. It is generally accepted that in an industrial society the priority is organic solidarity, individualism, obtaining maximum income with minimum costs; career within the corporate structure. Whereas sustainable development requires network solidarity, social orientation, socially-oriented production activities where the result depends on the ability to create a powerful image/brand of the product and spread through communication channels. Sustainable development requires dynamic stability, depending on the creative potential of a person/group of people and the communicative capital of this person/group of people.Building a society where the development and sustainable growth of the economy, population growth is combined with the preservation of the natural environment is possible only if the values of a "sustainable society" become close not to individual members of the elite but to a fairly large social group that is at an active age of 25-45 years, the middle productive class, connected with creative work rooted in the digital technology.

It is necessary to recognize the practical failure of plans for sustainable development due to the fact that the generation born in the twentieth century was unable to carry out a radical transformation of economic, political and social processes. Therefore, close attention is attracted by the generation born at the end of the 20th - at the beginning of the 21 st century called in Howe's terminology «Generation $Z$ ». In 2020 representatives of this generation have reached the age of majority work and/or study in higher educational institutions and in 10-15 years will play a significant role in global processes.

At the same time, we consider the generation not only as an aggregation delimited by age. We share the idea of $\mathrm{K}$. Mannheim about the importance of significant jointly experienced events for the formation of one generation or another [9], developed later by V.V. Radaev about the cumulative influence of all factors - economic, political, social - on the influence of a generation and the formation of a common or rather a similar set of values, specific for a given age aggregation. We understand the abstraction of the very concept of "generation" and the ability to identify only the most general features inherent not so much in the entire aggregation as in the aggregation of a given social group localized on a national or regional scale. 
Proceeding from the specifics, the subject of our research was determined by young people born in the late 1990s - early 2000s - students of the universities of Ufa both humanitarian and technical areas of training. This group can be extrapolated as future representatives of the cognitive that is, the productive middle layer of the information/digital society. The middle stratum, or the middle class in the terminology of A. Giddens, in our opinion, undergoes the greatest transformation and is forced to adapt to changing conditions, while the lower classes are busy with their survival, and the upper classes are too inert due to their possession of previously accumulated resources. Note that, by origin, university students studying in the region can be attributed to people from the middle class and the upper stratum of the lower class, while people from the upper classes tend to study in the capital's educational institutions or abroad and the supposed career trajectory was initially formed by a financially establishedfamily.

Generation $\mathrm{Z}$, in contrast to previous generations, is the first glocal generation in Russia, whose history of formation correlates with similar the history of developed countries of the world. The development of generation $\mathrm{Z}$ is under the influence of the transformation of both technological and social spheres with, in general, dynamically stable economic and political conditions typical for developed countries at that time. The earlier generation $\mathrm{X}$ was formed during the Cold War and stagnation in the USSR, while generation $\mathrm{Y}$ in our country experienced a psychological "collision" during the collapse of the country and further the formation of a new economic and political order in Russia in the 1980s-1990s. As for the generation Z, digital technologies came to them at the same time, as in all developed countries they initially live in an "open society" in the terminology of K. Popper. Their way of life is similar to the way of life of the younger generation in Europe and the United States, taking into account of course the local characteristics of Russian society.

As mentioned above, the creation of a society of sustainable development is possible with a change in value priorities on the scale of a generation. The purpose of this study was to identify such trends in the new generation $\mathrm{Z}$.

\section{Study methods}

This article presents an analysis of a part of the study of generation $\mathrm{Z}$ conducted by the Department of International Relations, History and Oriental Studies of USPTU in the summer of 2020. In general, the results of the study are reflected in the collective monograph of the authors of the article «Research on the complex of values of generation Z» published in October 2020. The complex of research included discourse analysis and machine content analysis of the text of more than 200 essays by first-year students, two stages of questionnaire with a total of more than 1000 participants, a series of focus groups and about thirty in-depth interviews. This article includes an analysis of materials from focus groups and in-depth interviews in terms of the value perception of the image of the future and survey data, mainly related to the perception of the past and the future in terms of building a society for sustainable development.

In connection with the pandemic of the new coronavirus infection in the summer of 2020 focus groups and in-depth interviews were conducted in the form of online videoconferences. That did not make significant changes in the behavior of respondents who had time to adapt to this mode of work. Taking into account the fact that all respondents are at least confident users of computer technology, it was decided to completely abandon the paper form of the questionnaire in favor of electronic "google" forms which greatly simplified both the collection of information and its analysis. A marker of the change in values is the significant difference in values among the group of Gen $\mathrm{Z}$ reviewers in comparison with the declared values of reviewers of older generations. 


\section{Literature Review}

Considering the complex of values of generation $\mathrm{Z}$ in Russia we rely on research on generational topics carried out by both domestic and foreign researchers in recent years. The timing of the research is especially important here since the time factor plays a special role in assessing the generation. From our point of view, it makes sense to consider foreign studies of the last five years, and domestic studies of the last three years, since it is at this time that Generation $\mathrm{Z}$ reaches majority and begins to take part in the economic, social and political processes of society as self-sufficient actors.We consider one of the most important international studies to be the large-scale studies by PewResearch Center conducted in the USA, East Asia and a number of other regions in 2018-2020 years (pewsocialtrends.org, 2020) [1] and McKinseyCompani's 2018-2020 Global Gen Z Consumer Research in Asia and America (mckinsey.com, 2018) [2] These studies were aimed at identifying the current preferences of the younger generation in the field of political, economic and social preferences. Based on the analysis of the data obtained, a short-term forecast was drawn up of the participation of the younger generation in elections, attitudes towards other ethnic groups and cultures of consumer behavior. In understanding the values of the previous generation $\mathrm{Y}$, the work of $\mathrm{V}$. Radaev had a great influence [3] «Millennials: How Russian Society is Changing», which highlighted the significant differences between Russian millennials. Despite the fact that those born in the 1980 s and early 1990 s can be very conditionally attributed to the generation of «digitalnatives» [4] this generation $\mathrm{Y}$ is actively mastering digital technologies like their peers in developed countries, at the same time, the social situation at the time of their birth was significantly different. The collapse of the USSR and the entire world socialist system, economic reform with the collapse of the entire economic system, dramatic events in political life, one way or another, affected the formation of generation Y. In addition to the characteristic features of the generation indicated by V. Radaev - individualism, a propensity to play, an idealistic attitude to society we would like to note infantilism, adherence to corporate values, striving for incorporation with the elite. These features are the result of society's adaptation to the permanent crisis of the 1990s in Russia, as well as the growing role of state participation in all social structures, including neo-institutional informal organizations.

The change of generations from $\mathrm{Y}$ to $\mathrm{Z}$ took place during the transition to a new stage of civilizational development - the stage of formation of the information society. We cannot agree with the opinion of V. Radaev that the differences between generations are only quantitative and not qualitative, that «the mechanics of its movement have already been largely determined» [3]. The influence of social processes on the formation of a generation has led to significant transformations in both society, institutions and organizations, groups of people and individuals, including (predominantly) the younger generation entering the world that is going to remake.

\section{Research results and conclusions}

When analyzing the results of the study, special attention was paid to the difference between participants in generation $\mathrm{Z}$ and the previous generation - Y, which either confirmed or refuted our hypothesis about a change in the value paradigm in the new generation. Despite the fact that the representatives of both generations are classified as "youth" and the generation formed under the influence of digital technologies, their attitude to the past, future and present are different. 
Generation $\mathrm{Y}$ is characterized by an opinion about the cyclical nature of historical processes. "History teaches nothing, and cannot teach... History is cyclical, knowing the history we can predict some circumstances"

Gen $\mathrm{Z}$ members have a different opinion. "History is what was before us... What is happening now will go down in history... History is the traversed path of mankind ...". And at the same time, in the opinion of Generation Z, the past is a useful source of information when using a certain assessment methodology. "History shows mistakes, merits of humanity, etc. The most important thing is how you comprehend it". The new generation presupposes to form its own set of values, the past is not an absolute value for it but an opportunity to identify the mechanism of the emergence of problems of the present.

The perception of the present also differs. For Y, the problems of the modern world are a given. "We are destroying the environment ... eating chemical food ... Among other important problems are poverty, material inequality". As expected, Gen Z entering independent life recognizes problems as created by previous generations. "Geopolitics.Ethics.Environment. What we are doing now is not enough. If we do nothing, the problem will develop into a global catastrophe". This difference is further defined in the answers to the question of who should solve this problem. If the participants of Generation $\mathrm{Y}$ have a widespread desire to assign this mission to an abstract "state", "international organizations" then the participants of Generation Z have a constructive approach: "Society must solve problems right now... We must consider ways to solve these problems, help, recreate something and create ... Everyone should solve these problems ... any person, including me".

Generation $\mathrm{Z}$ has a personal attitude to what is happening in the present and future. There is a widespread perception of the special role of their digital generation. They are ready not only to successfully function in a digital society themselves, but also to teach modern technologies to the older generation. "We are more or less ready ... the ancestors will not be able to adapt, it is too difficult for them. ... I will help them figure it out". Young people realize that the new world of digital society, understandable and natural for them, is new and alien for older generations. The rapidity of change created a unique situation of retrograde transfer of experience from younger to older, which in turn contributed to the strengthening of strong bonds in small groups. This trend is also noted in the analysis of questionnaires. To the question: "What values, in your opinion, are the most important in a person's life?" the most popular answer was "Health", which was natural given the COVID19 pandemic that took place during the survey.

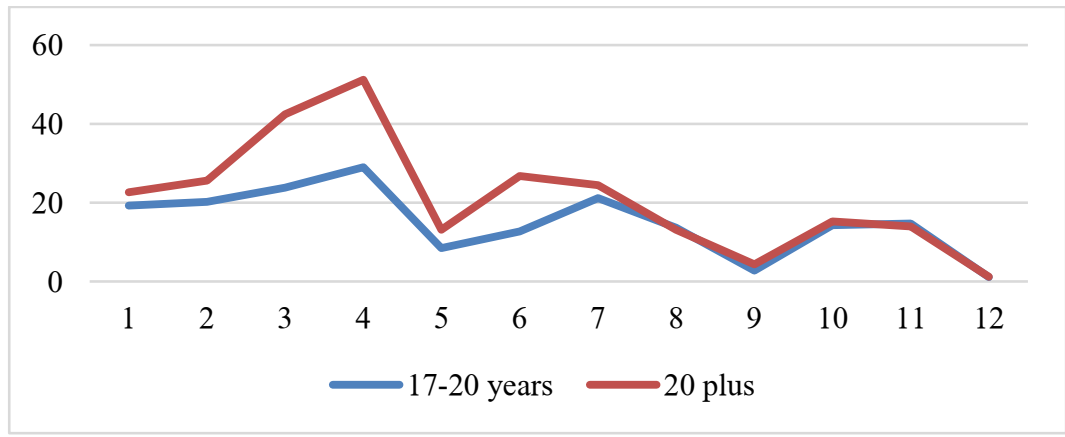

Fig.1. Question: What values do you think are the most important in a person's life.

Horizontal answer options: 1 . Historical memory; 2 . Justice; 3 . Achieve family happiness 4 . Health; 5. Patriotism; 6. Safety; 7. Personal freedom and independence; 8. Faithful friends; 9. Glory and recognition; 10. Real love; 11. Career and financial wealth; 12.Cannot say. 
The second most popular answer among Generation Z - No. 3 - "family happiness", as well as among the older generation. The third most popular answer for $\mathrm{Z}$ is personal freedom and independence, and for the older generation - security (see Figure 1). When analyzing the answers, you need to take into account age differences. Family happiness for generation $\mathrm{Z}$ is a given, that is, an existing family, while for the older generation it is a newly created (future) family. Family and a circle of friends form strong bonds, which include bonds formed on an axial basis associated with the proximity of values, communication codes, etc. Starting with M. Grannowetter, it is customary to talk about the strength of weak ties [6] that manifest themselves in the corporate sphere. But at present, the trend is reversed. New tribalism predicted by M.G. McLuhan, in reality manifested itself in generation $\mathrm{Z}$ in a tendency to strengthen strong ties, including in connection with a higher dynamics of information exchange than in previous generations and a greater mutual permeability of many communities.

At the second stage of the questionnaire, where the most characteristic behavioral reactions were determined, the desire for strong connections was also traced. Answers to the question "What can distract you from what you love?" were distributed almost the same for participants of all age categories, with the exception of answer No. 4 "Urgent call to a meeting with a friend" among participants of generation $\mathrm{Z}$.

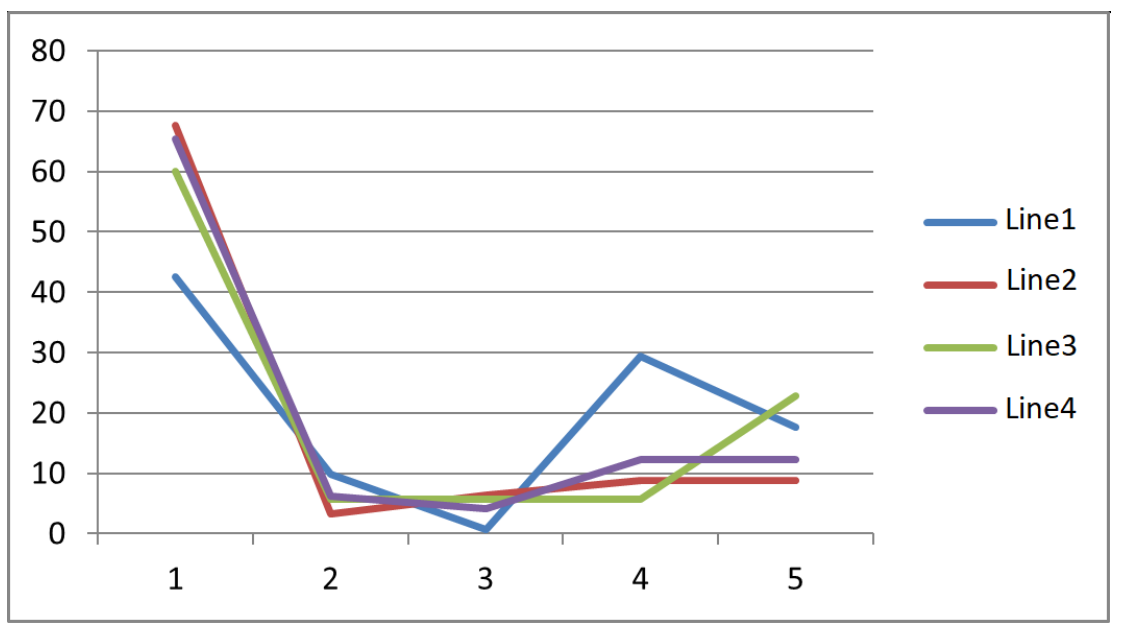

Fig. 2. Question: What can distract you from what you love? Answer options: №1. an important message from your boss, work or school colleague; №2. a special song from the playlist; №3. start of television broadcast; № 4. urgent call to meet with a friend;№.5. according to your schedule, it's time for lunch, workout, trip.

The analysis of essay texts written by junior students of Ufa universities also proved to be informative about the values of Generation Z. After conducting a discourse analysis of more than 200 essays, a generally positive attitude towards the future was revealed. Unlike the individualism of older generations, the essay mostly uses the pronoun "we" in relation to oneself and the generation as a whole. Students position themselves as an integral part of society, and the society that they intend to create. The adherence to personal responsibility and involvement is revealed: "We do not stand still, and what now seems to us fantasy will soon turn out to be a reality that we will accept and into which we will merge ... Today the world is changing before our eyes. The future is before us. And it will be the way we make it". The analysis of the essay reveals the values of sustainable development: efficient and rational use of resources, reducing inequality in human society, attention to social justice. 


\section{Acknowledgements}

The authors thank the staff of the Department of International Relations, History and Oriental Studies of USPTU, the management of the Institute of Economics and Service of USPTU, as well as USPTU students with whose active participation the research was carried out in a short time and with great quality.

The research was carried out within the framework of the project "Civil-patriotic platform" 75th anniversary of Victory: connection of generations "implemented by the Union of Russian Veterans with the support of the Civil Society Development Fund for the Grant of the Head of the Republic of Bashkortostan for the development of civil society.

\section{References}

1. K. Parker, R. Igelnik, On the Cusp of Adulthood and Facing an Uncertain Future: What We Know About Gen Z So Farh, https: //www.pewsocialtrends.org/

2. T. Francis T, F. Hoefel, 'True Gen': Generation $Z$ and its implications for companies, https://www.mckinsey.com/

3. V. Radaev, Millennials: How Russian society is changing (2020).

4. S. Bennett, K. Maton, L. Kervin, British Journal of Educational Technology, 5, 775 (2008)

5. M.S.Granovetter, American Journal of Psychology, 78(6), 1360 (1973)

6. Donella H. Meadows, Dennis L. Meadows, Jorgen Randers, William W. Behrens III, The Limits to Growth (1972)

7. Global Biodiversity Outlook.The future has arrived.Sustainable Development Report, 21 (2019)

8. Karl Mannheim, Essays on the sociology of knowledge: The Problem of Generations. Competition, Economic ambition, 13 (2000) 